\title{
Prevalence, Incidence and Characterization of Neurocognitive Impairment in Acute Coronary Syndrome. A Systematic Review and Meta-Analysis.
}

\author{
Eduarda Pereira ${ }^{1}$, Muriela Silva $^{1}$, Bruno Peixoto $^{2,3^{*}}$ \\ ${ }^{1}$ CESPU, Institute of Advanced Research and Training in Health Sciences. Gandra/Portugal \\ ${ }^{2}$ CESPU, University Institute of Health Sciences. Gandra/Portugal \\ ${ }^{3}$ NeuroGen - Center for Health Technology and Services Research (CINTESIS). Porto/Portugal
}

*Corresponding author: Peixoto B, CESPU, Instituto Universitário de Ciências da Saúde, Gandra and NeuroGen - Center for Health Technology and Services Research (CINTESIS) Portugal, E-mail: bruno.peixoto@iucs.cespu.pt

Citation: Peixoto B, Pereira E, Silva M (2016) Prevalence, incidence and characterization of neurocognitive impairment in acute coronary syndrome. A systematic review and meta-analysis. J Neurosci Neuropsyc 1: 102. doi: 10.18875/2577-7890.1.102

Article history: Received: 03 December 2016, Accepted: 30 January 2017, Published: 30 January 2017

\begin{abstract}
Background: Neuropsychological research in cardiovascular diseases has focused mainly in heart failure. The present systematic review aims to determine the incidence of neurocognitive dysfunction in acute coronary syndrome (ACS) and to define the neurocognitive functions most affected in ACS.

Methods: The systematic review was performed in June 2016 on Pubmed. No restrictions were established regarding publication date, language, age of the participants in each study, nor type of study or experimental design.

Results: Four studies were selected out of 74, once they address to at least one of the aims. The prevalence of neurocognitive dysfunction ranges between $10.51 \%$ and $66.8 \%$. We could determinate the incidence rate in two studies, ranging from 0.0277 cases per year to 0.416 cases per month. Alterations in verbal memory, language and executive functioning were found.

Conclusions: The variability of prevalence rates of neurocognitive dysfunction in ACS across studies may be due to the use of different neuropsychological instruments, different times of neuropsychological assessment and diverse demographical and clinical characteristics of the samples. In the future, further studies must clarify the neurocognitive tests that are more sensitive to ACS. The study of the interaction between risk factors, biomarkers, behavioral and environmental aspects as well as the clinical features of ACS and its treatment on brain and neurocognitive functioning, should also be clarified.
\end{abstract}

Keywords: Cardiovascular diseases; Incidence; Neuropsychological assessment; Cognitive impairment

\section{Introduction}

Cardiovascular diseases (CD) are the main cause of mortality and morbidity in Europe [1,2]. The acute coronary syndrome (ACS) is the most prevalent CD in developed countries, for both genders [3]. ACS is the result of the rupture or erosion of the atherosclerotic plaque, with several degrees of thrombosis and distal embolization [4].

Several studies have pointed to a prior history of ACS in dementia patients [5]. In fact, it has been established that ACS patients have a five times greater risk of developing any form of dementia [6]. This observation relates to the increased risk of cerebrovascular insults, such as ischemic stroke and transient ischemic attack, in the context of coronary disease and also implies a vascular basis for neurodegenerative conditions such as Alzheimer's disease [7].

Prospective studies point to the relation between several cardiovascular diseases such as ACS and lower performance on neurocognitive screen measures [8]. Neuropsychological research on CD has focused mainly in heart failure, a common denominator to several cardiac pathologies including ACS. Deficits in executive functioning, reduction in simple attention tasks, psychomotor speed, immediate memory and mental processing speed have been reported $[9,10]$. At six years follow-up of these patients showed a mild but significant decline of visual memory, visuoconstructive ability, verbal fluency, executive and global cognitive functioning [11]. However, the inclusion of heart failure patients with other CD diseases other than ACS, makes it difficult to determine the incidence and the characterization of neurocognitive deficits.

In this context, the present systematic review aims to answer to two questions: What are the prevalence and incidence rates of neurocognitive dysfunction in ACS?; What are the neurocognitive functions most affected in ACS? 


\section{Methods}

The systematic review was performed in June 2016 based on Pubmed (US National Library of Medicine National Institutes of Health). No restrictions were established regarding publication date (since the beginning to June 2016), language, age of the participants in each study, nor type of study or experimental design. We used the following search terms: [acute coronary syndrome ${ }^{*}$ AND (neurocognition OR cognition OR neuropsychological OR neuropsychology OR "cognitive impairment" OR dementia)].

\section{Results}

The search generated 74 papers (original $=52$; review $=18$; clinical cases $=4$ ). 40 were excluded because they referred to intervention, evaluation and monitoring of risk factors (e.g. Diabetes, hypertension, depression, obesity) and mortality in ACS. 17 papers were excluded for being out of the strict scope of ACS (e.g. Stroke, heart failure). 11 works were related to ACS in other pathologies (e.g. Cancer, dementia) and therefore were also excluded (Figure 1). 2 works were excluded due to the fact that none of the authors of this review were sufficiently proficient in the language of those papers. One was written in Japanese and other in Norwegian. Only four papers were selected due to the fact that they provide answer at least to one of the formulated questions (Table 1). For each work prevalence was determined by using the formula:

(Number of current cases (new and preexisting) at a specified point in time/Population at the same specified point in time) $\times 100$ Incidence rate was determined in two studies through the following formula:

Number of new cases of disease during specified time interval/ Summed person years of observation or average population during time interval.

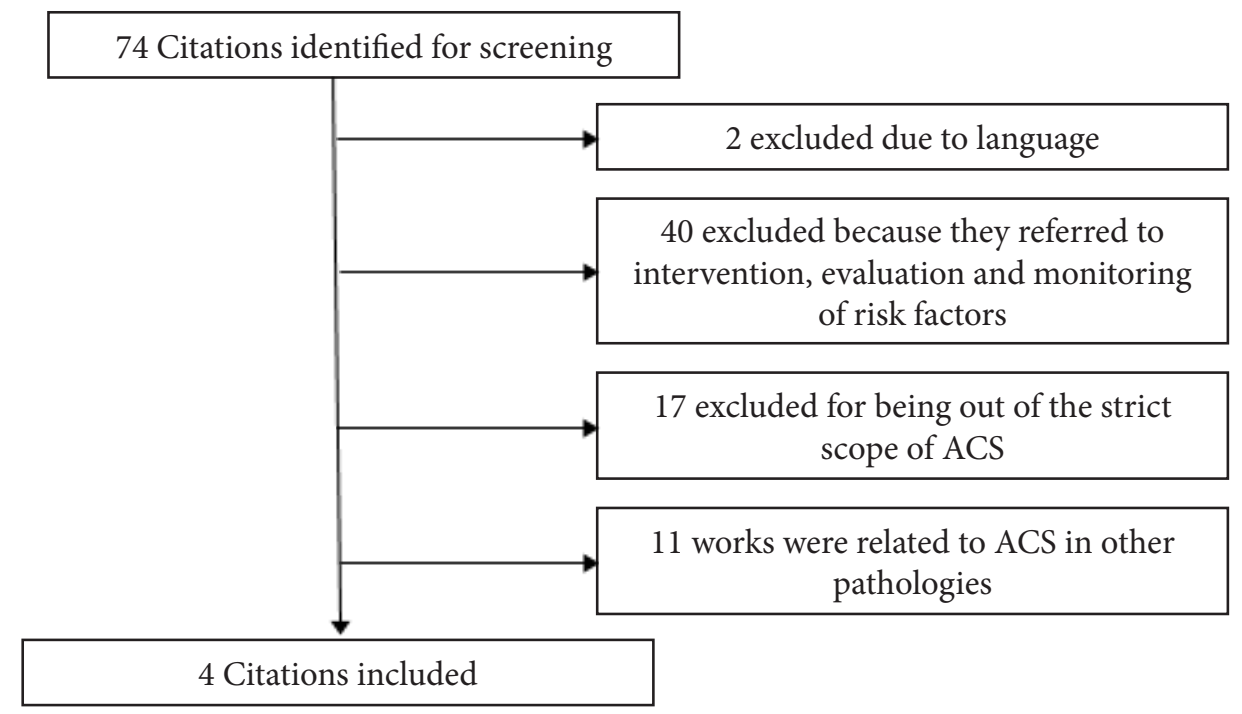

Figure 1: Study attrition diagram

\begin{tabular}{|c|c|c|c|c|c|c|}
\hline Study & $\begin{array}{l}\text { Experimental } \\
\text { design }\end{array}$ & Participants & Aims & $\begin{array}{l}\text { Conclusions related to } \\
\text { the questions }\end{array}$ & $\begin{array}{l}\text { Prevalence and } \\
\text { Incidence of } \\
\text { Neurocognitive } \\
\text { dysfunction }\end{array}$ & Other conclusions \\
\hline $\begin{array}{c}\text { Maerzec } \\
\text { et al., 2015 } \\
{[12]}\end{array}$ & $\begin{array}{l}\text { Prospective } \\
\text { study }\end{array}$ & ACS, $n=238$ & $\begin{array}{l}\text { To describe the } \\
\text { prevalence of } \\
\text { neurocognitive } \\
\text { dysfunction and } \\
\text { health literacy in } \\
\text { ACS patients }\end{array}$ & $\begin{array}{c}52 \% \text { of participants had } \\
\text { mild neurocognitive } \\
\text { disorder and } 14.8 \% \text { had } \\
\text { dementia }\end{array}$ & Prevalence: $66.8 \%$ & $\begin{array}{l}\text { Neurocognitive } \\
\text { dysfunction and } \\
\text { poor health literacy } \\
\text { are common in } \\
\text { ACS patients. Mild } \\
\text { neurocognitive } \\
\text { disorder was associated } \\
\text { to medication } \\
\text { nonadherence }\end{array}$ \\
\hline $\begin{array}{c}\text { Mixon et } \\
\text { al., 2014 } \\
{[13]}\end{array}$ & $\begin{array}{l}\text { Prospective } \\
\text { study }\end{array}$ & $\begin{array}{c}\text { ACS; } n=333 ; \\
\text { HF, } n=99 ; \\
\text { ACS and } \\
H F=39\end{array}$ & $\begin{array}{l}\text { To analyse the } \\
\text { association of } \\
\text { patient and } \\
\text { medication-related } \\
\text { factors with } \\
\text { post-discharge } \\
\text { medication errors. }\end{array}$ & $\begin{array}{l}7.4 \% \text { of the total } \\
\text { sample had deficitary } \\
\text { general neurocognitve } \\
\text { functioning }\end{array}$ & Prevalence: $10.51 \%$ & $\begin{array}{l}51 \% \text { of the patients } \\
\text { with ACS and HF had } \\
\text { at least one discordant } \\
\text { medication after } \\
\text { discharge; worse } \\
\text { cognitive function } \\
\text { was associated to } \\
\text { higher odds of } \\
\text { misunderstanding } \\
\text { in frequency of } \\
\text { medication. }\end{array}$ \\
\hline
\end{tabular}




\begin{tabular}{|c|c|c|c|c|c|c|}
\hline Study & $\begin{array}{c}\text { Experimental } \\
\text { design }\end{array}$ & Participants & Aims & $\begin{array}{l}\text { Conclusions related to } \\
\text { the questions }\end{array}$ & $\begin{array}{l}\text { Prevalence and } \\
\text { Incidence of } \\
\text { Neurocognitive } \\
\text { dysfunction }\end{array}$ & Other conclusions \\
\hline $\begin{array}{l}\text { Volonghi } \\
\text { et al., } \\
2013[14]\end{array}$ & $\begin{array}{l}\text { Longitudinal } \\
\text { study }\end{array}$ & $\begin{array}{c}\text { ACS, } n=216 ; \\
\text { TIA, } n=182 ; \\
\text { Minor stroke, } \\
\quad n=216\end{array}$ & $\begin{array}{l}\text { To study the } \\
\text { neurocognitive } \\
\text { outcomes } 1 \text { and } \\
5 \text { years after ACS } \\
\text { versus TIA and } \\
\text { minor stroke. }\end{array}$ & $\begin{array}{c}9 \% \text { of ACS } \\
\text { patients presented } \\
\text { neurocognitive } \\
\text { dysfunction at } 1 \text { year } \\
\text { even when compared } \\
\text { to TIA and minor } \\
\text { stroke patients. } 5 \text { years } \\
\text { after the ACS, } 10.2 \% \text { to } \\
63 \% \text { showed deficitary } \\
\text { general neurocognitive } \\
\text { functioning }\end{array}$ & $\begin{array}{c}\text { Prevalence at } 1 \\
\text { year: } 9 \% \text { Prevalence } \\
\text { at } 5 \text { years: } 10.2 \% \\
\text { determined by MMSE } \\
\text { and } 63 \% \text { determined } \\
\text { by MoCA Incidence } \\
\text { rate ( } 5 \text { year period): } \\
0.0277 \text { cases per } \\
\text { person-year }\end{array}$ & $\begin{array}{l}\text { Risk of cognitive } \\
\text { impairment after ACS is } \\
\text { similar to minor stroke } \\
\text { and higher than TIA } \\
\text { with implications for } \\
\text { consent and adherence } \\
\text { to medication. } \\
\text { Cognitive performance } \\
\text { in ACS is suggestive } \\
\text { of degenerative brain } \\
\text { pathology }\end{array}$ \\
\hline $\begin{array}{l}\text { Bernard et } \\
\text { al., 2015 } \\
{[15]}\end{array}$ & $\begin{array}{l}\text { Longitudinal } \\
\text { study }\end{array}$ & ACS, $n=33$ & $\begin{array}{l}\text { To investigate the } \\
\text { cerebral anatomo- } \\
\text { functional } \\
\text { substratum } \\
\text { of executive } \\
\text { dysfunction }\end{array}$ & $\begin{array}{l}\text { At baseline, } 36.1 \% \\
\text { of patients presented } \\
\text { impaired executive } \\
\text { function. At } 6 \text { months, } \\
24.2 \% \text { were classified } \\
\text { as "impaired", } \\
30.3 \% \text { as "transient } \\
\text { impaired" and } 45.5 \% \text { as } \\
\text { "cognitively normal" }\end{array}$ & $\begin{array}{l}\text { Prevalence at baseline: } \\
36.1 \% \text { Prevalence } \\
\text { at } 6 \text { months: } 24.2 \% \\
\text { Incidence rate ( } 6 \\
\text { month period): } 0.416 \\
\text { cases per person- } \\
\text { month }\end{array}$ & $\begin{array}{l}\text { Executive dysfunction } \\
\text { is associated to } \\
\text { functional but } \\
\text { no structural } \\
\text { characteristics, } \\
\text { particularly to an } \\
\text { increased functional } \\
\text { connectivity }\end{array}$ \\
\hline
\end{tabular}

ACS: Acute Coronary Syndrome; TIA: Transient Ischemic Attack; HF: Heart Failure; MMSE: Mini Mental State examination; MoCA: Montreal Cognitive Assessment Table 1: Summary of the selected studies

\section{Discussion}

The present review aimed to determine the prevalence and incidence of neurocognitive dysfunction and to identify the main neurocognitive deficits in ACS.

The prevalence of neurocognitive dysfunction ranges between $10.51 \%$ and $66.8 \%$. The study reporting higher prevalence level [12], classified $52 \%$ of participants as having mild cognitive disorder and $14.8 \%$ having dementia. The majority of the participants in that study had a prior history of coronary heart disease and a high degree of comorbidities, such as diabetes, chronic kidney disease and depression. The authors have found an association between cognitive dysfunction and medication nonadherence, especially in patients with mild cognitive disorder [12]. In this study, the time elapsed since the ACS and neuropsychological assessment is not clear.

The study of Mixon and colleagues [13], assessed patients shortly after admission. 8\% of the participants received a diagnosis of both ACS and acute decompensated heart failure. This study found an association between worse cognitive dysfunction and misunderstanding in frequency of medication [13]. Considering ACS patients only, the prevalence of neurocognitive dysfunction is $10.52 \%$.

The study of Volonghi and colleagues [14], points to higher rates of neurocognitive dysfunction at 1 year and 5 years after ACS in comparison to transient ischemic attack (TIA) and minor stroke patients. 9\% of ACS patients presented neurocognitive dysfunction at 1 year and did worse on Mini Mental Sate Examination (MMSE) when compared to TIA and minor stroke patients. Five years after the ACS, 10\% of the patients obtained scores below the cut-off on MMSE and 63\% showed deficitary results on Montreal Cognitive Assessment (MoCA). At this period, ACS patients general level of neurocognitive functioning was similar to those with TIA or minor stroke [14]. During the five year period the common denominator of neuropsychological assessment was the use MMSE. Thus, taking that into account, the incidence rate in this study was 0.0277 cases per person-year.

Bernard and colleagues [15] focused on executive functioning 4 and 6 months after ACS. At baseline, $36.1 \%$ of patients presented impaired executive function. At follow-up, $76.9 \%$ of the impaired improved their performance and $34.8 \%$ of the unimpaired became impaired. In consequence, at 6 months, $24.2 \%$ were classified as "impaired", $30.3 \%$ as "transient impaired" and $45.5 \%$ as "cognitively normal" [15]. We have found an incidence rate of 0.416 cases per person-month in this study.

Regarding the neurocognitive functions most affected in ACS, this systematic review points to alterations in verbal memory, language and executive functioning.

In comparison to TIA and minor stroke, ACS patients did worth on MMSE recall on both 1 and 5 years and on repetition at 1 year. At 5 years, ACS patients had greater impairment on MoCA recall and language items than cerebrovascular groups [14]. In this study the number of vascular risk factors was associated to higher rates of cognitive impairment. Executive functioning it is also compromised. However, the determination of executive functioning was made only through the Trail Making Test B, thus limiting the wide use of this term on the context of ACS. Difficulties in working memory and secondarily in task-switching abilities seem to be more suitable to characterize these patients. These alterations are associated to an increased functional connectivity in medialorbito-frontal region [15]. 


\section{Conclusion}

The variability of prevalence rates of neurocognitive dysfunction in ACS across studies may be due to the use of different neuropsychological instruments. None of the four selected studies used the same neuropsychological test. Testing was preformed through several instruments such as the St Louis University Mental Status [12], Short Portable Mental Status Questionnaire [13], MMSE and MoCA [14] and the Trail Making Test [15]. Variations between studies concerning the time of the neuropsychological assessment, demographical and clinical characteristics (e.g. treatment, type of ACS, comorbidities) of the samples, may also contribute to the observed differences. In fact, these variations between studies make the determination of a neurocognitive profile in the ACS very difficult.

In the future, further studies must clarify the neurocognitive tests that are more sensitive to ACS and its resilience and vulnerability factors [16]. The inclusion of more extensive neurocognitive measures into epidemiological studies, may offer the opportunity to track trajectories of domain-specific decline [16]. The study of the interaction between risk factors, biomarkers, behavioral and environmental aspects as well as the clinical features of ACS and its treatment on brain and neurocognitive functioning, should also be clarified [17]. Unveiling these interactions may point to new therapeutic targets aiming to prevent brain dysfunction and neurocognitive impairment [17].

\section{References}

1. Nichols M, Townsend N, Scarborough P, Rayner M (2013) Cardiovascular disease in Europe: epidemiological update. Eur Heart J 34: $3028-34$.

2. World Health Organization (2004) The atlas of heart disease and stroke, Geneva.

3. Elsaesser A, Hamm CH (2004) Acute coronary syndrome: the risk of being female. Circulation 10: 565-7.

4. Hamm CH, Bassand JP, Agewall S, Bax J, Boersma E, et al. (2011) ESC Guidelines for the management of acute coronary syndromes in patients presenting without persistent ST-segment elevation: The Task Force for the management of acute coronary syndromes (ACS) in patients presenting without persistent ST-segment elevation of the European Society of Cardiology (ESC). Eur Heart J 32: 2999-3054.

5. Rusanen M, Kivipelto M, Levälahti E, Laatikainen T, Tuomilehto J, et al. (2014) Heart diseases and long-term risk of dementia and Alzheimer's disease: a population-based CAIDE study. J Alzheimers Dis 42: 183-91.

6. Aronson M K, Ooi W L, Morgenstern H, Hafner A, Masur D, et al. (1990) Women, myocardial infarction, and dementia in the very old. Neurology 40: 1102-6.

7. de la Torre JC (2004) Is Alzheimer's disease a neurodegenerative or a vascular disorder? Data, dogma, and dialectics. Lancet Neurol 3: 184-90.

8. Singh-Manoux A, Britton AR, Marmot M (2003) Vascular disease and cognitive function: evidence from the Whitehall II Study. J Am Geriatr Soc 51: 1445-50. 9. Hoth KF, Poppas A, Moser DJ, Paul RH, Cohen RA (2008) Cardiac dysfunction and cognition in older adults with heart failure. Cogn Behav Neurol 21: 65-72.

10. Eggermont LH, De Boer K, Muller M, Jaschke AC, Kamp O, et al. (2012) Cardiac disease and cognitive impairment: a systematic review. Heart 98:1334-30.

11. Selnes OA, Grega MA, Bailey MM, Pham LD, Zeger SL, et al. (2009) Do management strategies for coronary artery disease influence 6-year cognitive outcomes? Ann Thorac Surg 88: 445-54.

12. Marzec LN, Carey EP, Lambert-Kerzne AC, Del Giacco EJ, Melnyk SD, et al. (2015) Cognitive dysfunction and poor health literacy are common in veterans presenting with acute coronary syndrome: insights from the MEDICATION study. Patient Prefer Adherence 9: 745-51.

13. Mixon AS, Myers AP, Leak CL, Lou Jacobsen JM, Cawthon C, et al. (2014) Characteristics associated with post-discharge medication errors. Mayo Clin Proc 89: 1042-51.

14. Volonghi I, Pendlebury ST, Welch SJ, Mehta Z, Rothwell PM (2013) Cognitive outcomes after acute coronary syndrome: a population based comparison with transient ischaemic attack and minor stroke. Heart 99: 1509-14.

15. Bernard C, Catheline G, Dilharreguy B, Couffinhal T, Ledure S, et al. (2016) Cerebral changes and cognitive impairment after an ischemic heart disease: a multimodal MRI study. Brain Imaging Behav 10: 893-900.

16. Armstrong CL, Morrow L (2010) Cardiovascular disease and neurocognitive function In: Handbook of Medical Neuropsychology: Applications of cognitive neuroscience, New York: Springer, USA.

17. Peixoto B (2016) Acute coronary syndrome, brain and neurocognitve functioning. What's in between? Current Neurobiology 7: 11-12. 